\title{
MEASUREMENT OF INTRA-VAGINAL AND INTRA- UTERINE PRESSURES DURING HUMAN COITUS BY RADIO-TELEMETRY
}

\author{
C. A. FOX, ${ }^{*}$ H. S. WOLFF† AND J. A. BAKER $\dagger$ \\ *176 Charlton Road, London, S.E.7, and $\uparrow$ Division of Biomedical Engineering, \\ National Institute for Medical Research, London
}

(Received 23rd May 1969)

\begin{abstract}
Summary. Intra-vaginal and intra-uterine pressure changes during human coitus were monitored by the use of a pressure-sensitive radiopill.

Pressure was found to be negative in the vagina during intromission and male orgasm but became positive during female orgasm. In the uterus, the pressure changes were minimal during male orgasm but increased markedly during female orgasm to a positive pressure of $40 \mathrm{~cm} \mathrm{H} \mathrm{H}_{2} \mathrm{O}$, followed by a sharp fall after orgasm to a negative pressure of $26 \mathrm{~cm} \mathrm{H} \mathrm{H}_{2} \mathrm{O}$.

The reliability of these results is discussed in relation to their possible significance in the pattern of sperm transport, and it is suggested that the final negative pressure following female orgasm may effect an 'insuck' of the cervical mucus with its entrapped spermatozoa.
\end{abstract}

\section{INTRODUCTION}

The use of the radio-pill has been described by Wolff (1961). Pressure-sensitive pills have been used to study parturient pressures in the ovine uterus (Hindson, Schofield, Turner \& Wolff, 1965; Hindson, Schofield \& Turner, 1968), in the cow (Simmons, Dracy \& Essler, 1965), and in the rhesus monkey (Bangham, Cotes \& Parsons, 1966). The advantage of this method is that it obviates the use of a catheter with external attachments as described by Hendricks (1964), Gsapo \& Pinto-Dantas (1966) and Moawad \& Bengtsson (1967), which would be a hindrance in coital experiments.

The present study was undertaken in the hope that it might throw light on the functions of the uterus and particularly the part played by female orgasm in aiding transport of spermatozoa from the vagina to the uterus. For this reason, the spermatozoa were not allowed to come into contact with the vagina or uterus, i.e. a sheath was used during the experiments. It was, thus, hoped to obtain information relating solely to the female orgasm and its possible effects on uterine motility and pressures. 


\section{MATERIALS AND METHODS}

The apparatus consisted of a radio-pill, a loop aerial, a radio-receiver and a moving-coil pen recorder. With the pill in situ, the loop aerial was placed under the mattress of the bed where coitus took place and connected to the radioreceiver which stood by the bed. There were no wires or other external attachments to either of the subjects, the only requirements being that coitus took place with the pill within the boundaries of the loop aerial ( $40 \mathrm{~cm}$ square).

The experiments were carried out on an individual married couple aged 38 (male) and 33 (female) with 11 years' mutual coital experience. They took place in complete privacy in the habitual and familiar environment of their own bedroom.

The use of the pill intra-vaginally offered no problems but for intra-uterine use, strict asepsis was necessary for its introduction and the cervix was dilated under paracervical block in a hospital theatre to enable the pill to pass the internal os. A total of four separate experiments were carried out, two with the pill in the vagina and two with the pill in the uterus. The uterine experiments took place on Days 17 and 19 of a 33-day cycle, an average length of cycle for this subject.

The pressure-sensitive radio-pill used in these experiments measured $15 \mathrm{~mm}$ in length and $9 \mathrm{~mm}$ in diameter (Plate 1 ) and was of commercial manufacture (EIL, Richmond, Surrey). It differed from that previously described (Wolff, 1961) in that it had a replaceable battery and a metal cap, rather than a plastic diaphragm. The cap, giving access to the battery compartment, had a hole drilled through it so that a thread could be attached securely. The battery had a life of $48 \mathrm{hr}$. The receiver was a model manufactured by Selig Electromagnetics, capable of converting frequency deviations of up to 50 kilohertz $(\mathrm{kHz})$ into an output voltage linearly related to it. To obtain a recording, this voltage was fed into a conventional moving-coil pen recorder.

One of the practical difficulties encountered when using a radio-pill for measurement against the datum of the prevailing atmospheric pressure is that, once the battery compartment cap has been screwed home, all pressures are actually measured in relation to the pressure of the air trapped within the pill. The recordings obtained from the pill will, therefore, change with temperature and changes in barometric pressure will also be registered.

The atmospheric pressure lines which have been drawn on to the recordings have been derived from a reading taken after the pill had been extracted from the uterus and placed into a dish of water at $37^{\circ} \mathrm{C}$. Corrections have been made for the depth of water in the dish, for the deliberate offsetting of the tuning of the receiver, and for the changes in the barometric pressure. However, taking into account drift in the pill calibration during the experiment, and some uncertainty of the uterine temperature when the recordings were being made, an error of $\pm 5 \mathrm{~cm} \mathrm{H}_{2} \mathrm{O}$ in the position of the zero line is possible.

Radio-pills commonly have a sensitivity of $30 \mathrm{kHz} / 100 \mathrm{~cm} \mathrm{H} \mathrm{H}_{2} \mathrm{O}$. The sensitivity of the recorder output of the receiver was adjusted to be $100 \mathrm{~cm} \mathrm{H}_{2} \mathrm{O}$ for full-scale deflection of the recorder. 
PLATE 1

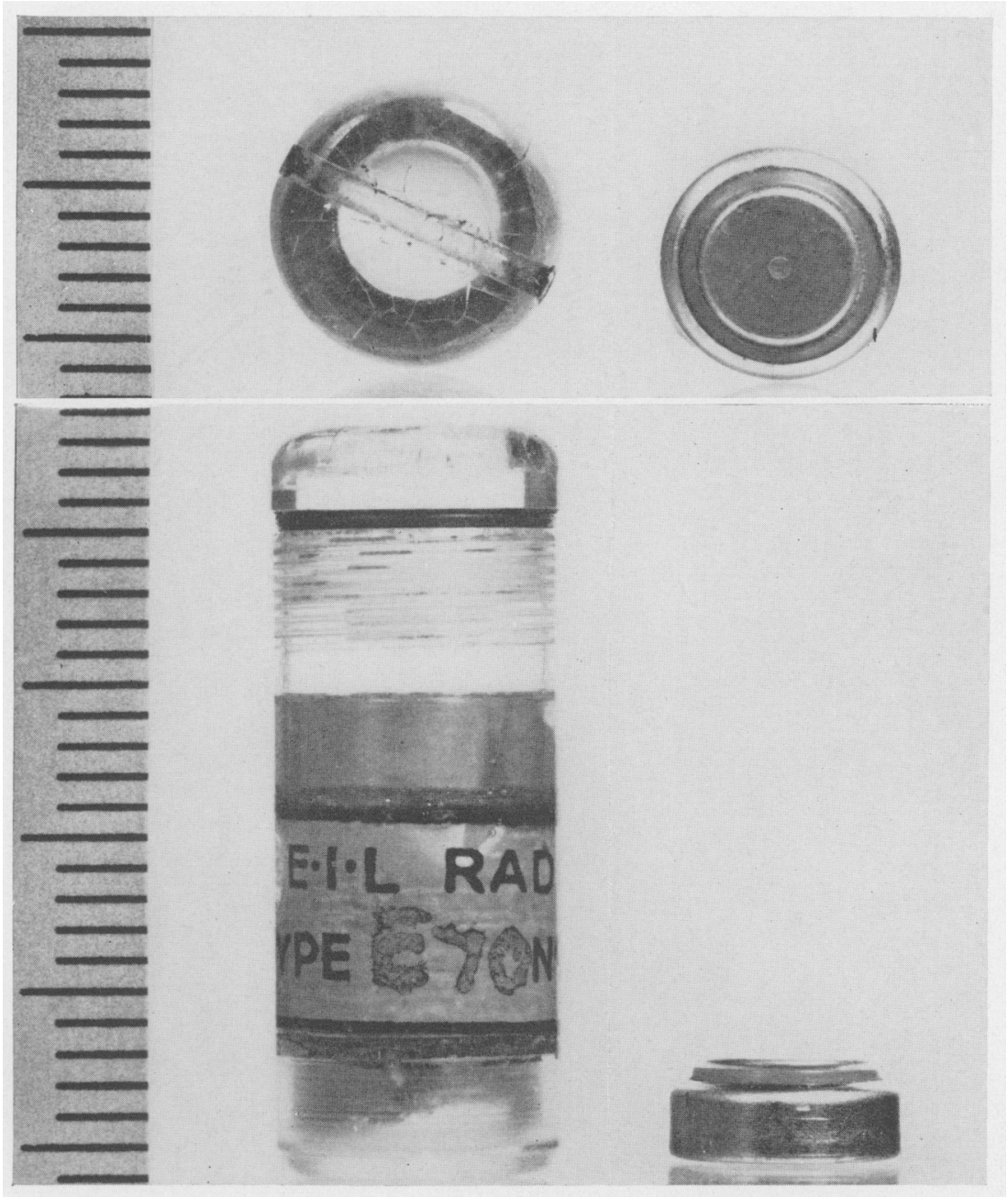

Photographs showing the diameter and length of a radio-pill similar to but larger than the one used. The object on the right of each photograph is the miniature mercury battery. The scales on the left are marked in millimetres. 

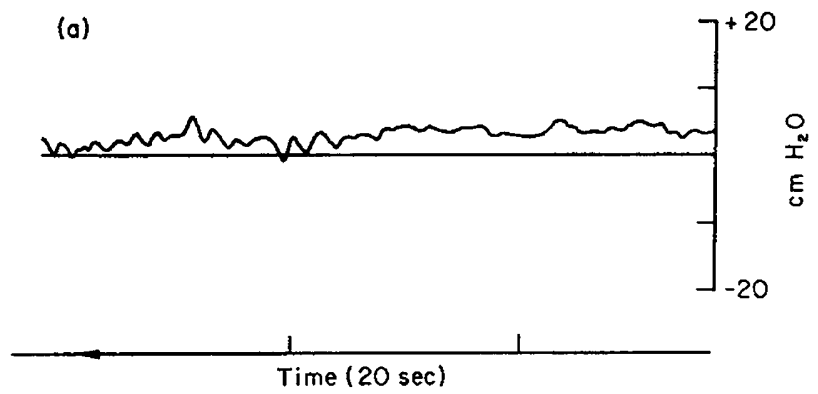

(b)
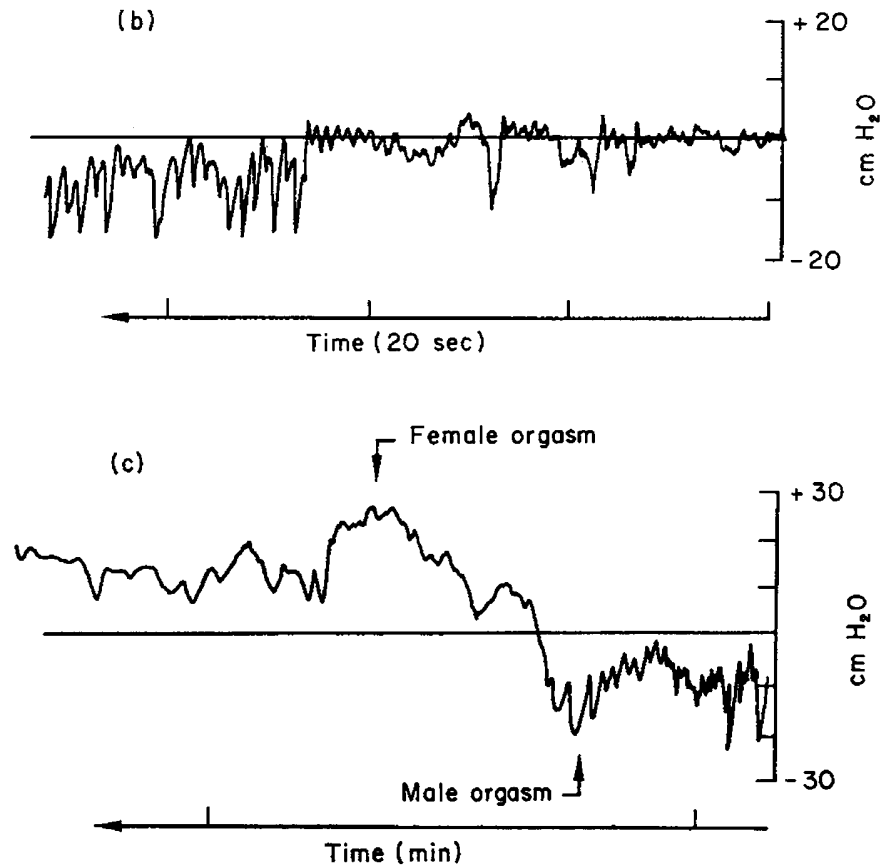

TexT-FIG. 1. Intra-vaginal pressure: (a) resting; (b) intromission; (c) male and female orgasm.

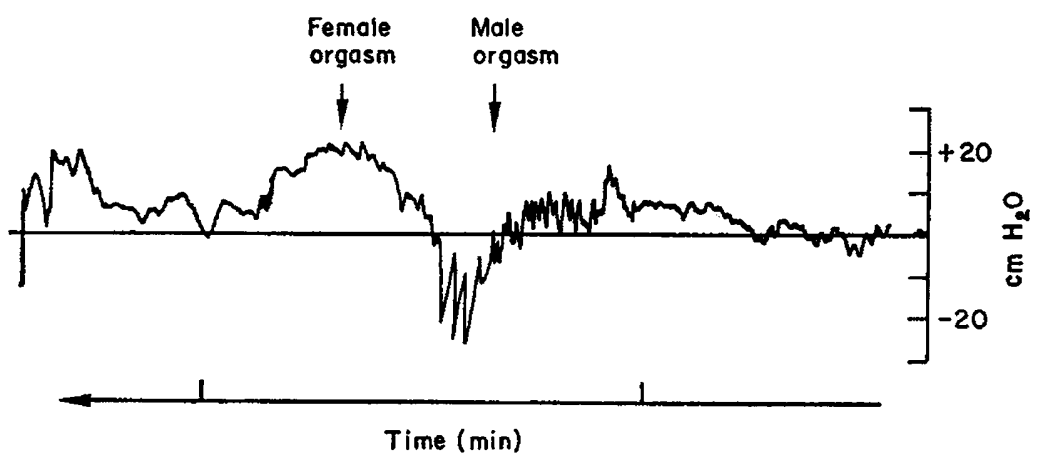

TEXT-rTG. 2. Intra-vaginal pressure (second experiment). Male and female orgasm. 


\section{RESULTS}

Recordings of intra-vaginal pressure changes are shown in Text-figs. la, b and c, and Text-fig. 2. The results of these separate experiments show that the findings are replicable. During intromission in the first experiment, the pressure in the

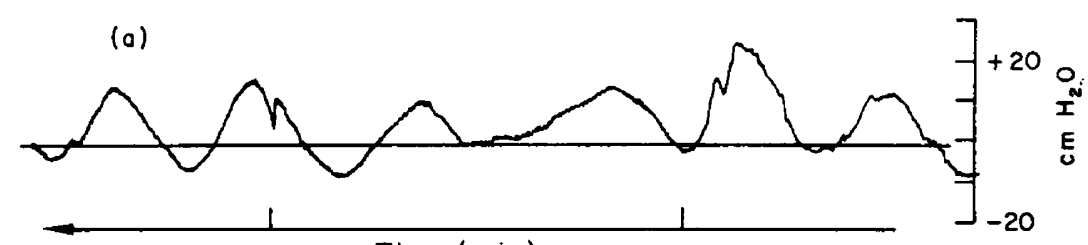

Time $(\min )$

(b)
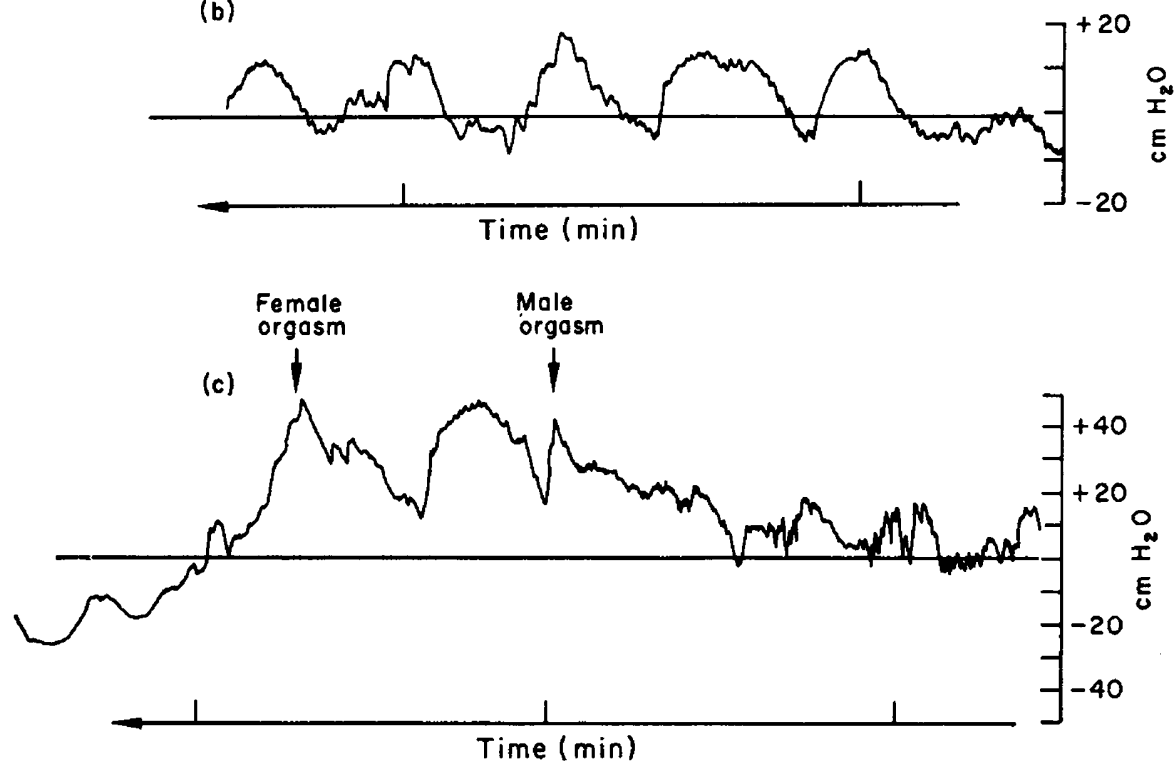

(d)

Return to regular contractions

Pressure rising

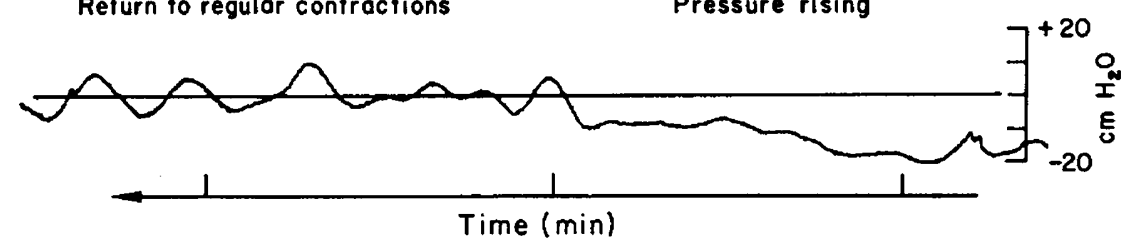

Text-FIG. 3. Intra-uterine pressure: (a) resting, note regular contractions; (b) intromission, regular contractions still visible; (c) male and female orgasm; (d) postorgasmic (female) phase, note return to regular contractions with similar pressure patterns to resting phase.

vagina fell to $-18 \mathrm{~cm} \mathrm{H}_{2} \mathrm{O}$ and during male orgasm, a further fall occurred to $-20 \mathrm{~cm} \mathrm{H} \mathrm{H}_{2} \mathrm{O}$. During female orgasm, the pressure rose to a peak of $+26 \mathrm{~cm}$ $\mathrm{H}_{2} \mathrm{O}$ (Text-fig. 1c). Similar changes occurred in the second experiment, a pressure of $+35 \mathrm{~cm} \mathrm{H}_{2} \mathrm{O}$ being recorded during female orgasm (Text-fig. 2). 
The intra-uterine pressures are shown in Text-figs.3a, b and c, and $4 \mathrm{a}$ and $\mathrm{b}$. Regular uterine contractions can be seen in Text-fig. 3a, representing the resting phase. These contractions occurred at the rate of four per minute and had the following quantitative value: $+12 \mathrm{~cm} \mathrm{H}_{2} \mathrm{O}$ pressure at their peak, and a small phase of negative pressure $\left(-2\right.$ to $\left.-6 \mathrm{~cm} \mathrm{H}_{2} \mathrm{O}\right)$ at their trough.

During intromission, the contractions could still be seen, (Text-fig. $3 \mathrm{~b}$ ). The pressure rose as male climax was reached and then fell sharply by $26 \mathrm{~cm} \mathrm{H}_{2} \mathrm{O}$, i.e. from $+42 \mathrm{~cm} \mathrm{H}_{2} \mathrm{O}$ to $+16 \mathrm{~cm} \mathrm{H}_{2} \mathrm{O}$ (Text-fig. 3c), with similar results in the second experiment (Text-fig. 4a). There was an increase in intra-uterine pressure as the female climax was reached, with two peaks of $+48 \mathrm{~cm} \mathrm{H}_{2} \mathrm{O}$ in the first uterine experiment (Text-fig. 3c), and $+40 \mathrm{~cm} \mathrm{H}_{2} \mathrm{O}$ in the second

(a)

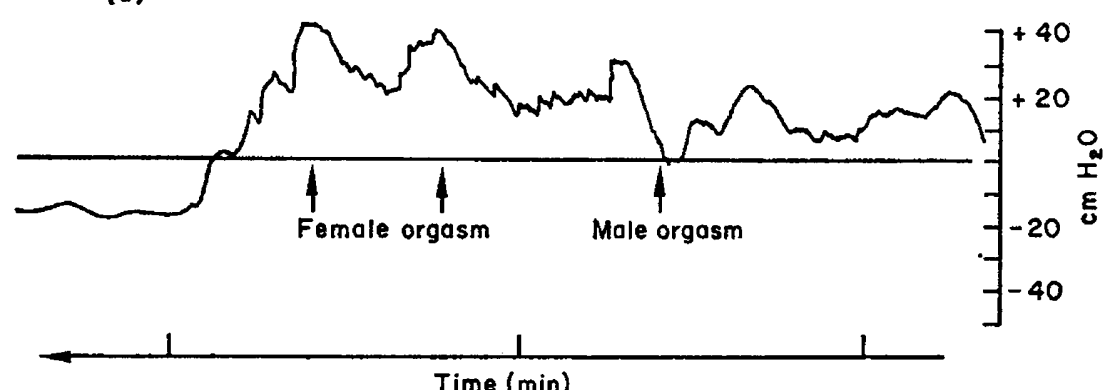

(b)

Regular contractions Pressure rising

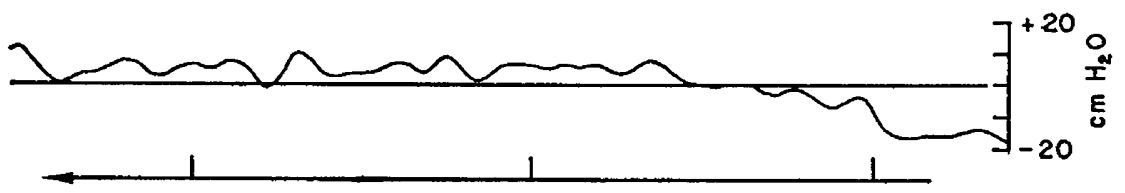

Time $(\min )$

TeXT-FIG. 4. Intra-uterine pressure (second experiment): (a) male and female orgasm;

(b) post-orgasmic (female) phase.

uterine experiment (Text-fig. 4a). There followed a sharp post-orgasmic fall in pressure to $-26 \mathrm{~cm} \mathrm{H} \mathrm{H}_{2} \mathrm{O}$ (Text-fig. 3c) and $-16 \mathrm{~cm} \mathrm{H}_{2} \mathrm{O}$ (Text-fig. 4a) in the two experiments. Following this, the pressure rose slowly over the next minute, during which time the uterus was relatively quiescent, and then the regular contractions returned (Text-figs. $3 \mathrm{~d}$ and $4 \mathrm{~b}$ ). When the regular uterine contractions had returned some $3 \frac{1}{2}$ min after female orgasm, they were of the same pressure, amplitude and level as in the resting phase before the experiment commenced.

\section{DISCUSSION}

Previous workers have disagreed on the part, if any, played by the uterus in sperm transport. Rapid passage of spermatozoa was first demonstrated by Hartman \& Ball (1930), who found spermatozoa in the Fallopian tubes of rats 
2 min after copulation. Similarly, VanDemark \& Moeller (1951) showed in the cow that an estimated sperm journey of $1 \frac{1}{2} \mathrm{hr}$ was accomplished in 2 to $3 \mathrm{~min}$. Evans (1933), using a uterine fistula technique, reported that spermatozoa arrived at the oviducts of the bitch within $25 \mathrm{sec}$ of ejaculation. He assumed that the spermatozoa were transported en masse by antiperistaltic waves. This experiment has been criticized because of the unnatural feature of making such a fistula. Ammersbach (1930), and Trapl (1943), report the passage of a suspension of carbon particles, and carmine particles, respectively, into the human uterus after coitus, though neither of these experiments is well documented.

Millar (1952) showed that a strong negative uterine pressure occurred during mating of the mare. He connected the uterus to a bottle of methylene blue by copper tube and reported a strong 'insuck' of this fluid, $80 \mathrm{ml}$ being aspirated within $5 \mathrm{sec}$. Krehbiel \& Carstens (1939) showed that after artificial stimulation of the vulva of rabbits, substances such as methylene blue, janus green B and iodochlorol were rapidly transferred from the vagina to the uterus. They concluded that the combined activity of the vagina and uterus was responsible for this transportation.

On the other hand, Walton (1930), and Carleton \& Florey (1931), failed to demonstrate the passage of pigment in experiments with rabbits, and dogs, respectively. Genell (1939), working with rats, cast doubt on the theory of uterine insuck, and postulated a plunging mechanism in which the ejaculated spermatozoa are "flung into the uterus". Since he used a cannula to distend the cervix, one may criticize this experiment as differing from the natural situation.

Noyes, Adams \& Walton (1958) could not demonstrate the passage of radioopaque oil or spermatozoa from vagina to uterus in rabbits which were artificially stimulated. They concluded that spermatozoa entered the uterus by their own motility. Grafenberg (1950) and Masters \& Johnson (1966) repeated this sort of experiment in humans, but were unable to demonstrate the entry of radio-opaque fluid from a cervical cap into the uterus after coitus and clitoral stimulation respectively. The latter experiment suffers from the fact that it was not performed under natural coital conditions, i.e. the stimulation was artificial. In human experiments, we have shown that pressure upon the abdomen by the hand, or in the coital situation by the male lying on the female, increases intra-uterine pressure by some $10 \mathrm{~cm} \mathrm{H}_{2} \mathrm{O}$ (Text-fig. 1c). In addition, the presence of the penis in the vagina alters the state of pressure in the vagina. Such factors cannot be taken into consideration in the experiments discussed so far.

\section{Experimental artifacts}

In attempting to make recordings of conditions accompanying coitus, it is impossible to eliminate experimental artifacts altogether, and it must therefore be our aim to keep them to a minimum. The artifacts of previous experiments fall into the following four categories:

(a) The use of a cervical cap which constricts the external os and prevents inward and outward flow of matter.

(b) Injection of fluids into the vagina ante coitum, causing vaginal distension prior to intromission. 
(c) Use of oils, particles of carbon and other foreign matter, which may differ substantially in weight and density from a material which is naturally appropriate, such as spermatozoa in seminal fluid, and

(d) The insertion of rigid tubes into the cervical canal, which hold it patent and impede its normal muscular activity.

In the case of the first three artifacts, false negative results may be more likely to occur than false positive ones, though in the latter case false positive results may be equally possible.

Whilst use of the radio-pill avoids the above artifacts, there remains, nevertheless, the disadvantage of a small foreign body within the uterus or in the vagina. Though tiny, it was effective enough to cause rejection by the uterus on the first insertion, and may therefore cause greater positive pressures than might occur under natural conditions.

Nevertheless, this would not account for the relative changes in pressure, especially at the points of orgasm, and the sudden rebound in pressure following upon orgasm.

\section{CONCLUSIONS}

The findings presented in this paper suggest that a pressure gradient exists between the vagina and the uterus immediately after female orgasm. This would lend support to the theory of uterine insuck, which supposes that the uterus plays an active part in the transport of semen from the vagina to the uterus. The activity of the uterus may be enhanced by the release of oxytocin into the bloodstream of the female at orgasm, for the presence of a small amount of this substance has been demonstrated in the peripheral blood of the human female within 1 min of orgasm (Fox \& Knaggs, 1969).

Amongst the contents of semen are certain factors such as the prostaglandins, which might affect uterine motility by direct contact (Eliasson \& Posse, 1965; Pickles, 1967). However, we have, as explained previously, concentrated on the effects of female orgasm on the uterus, and would suggest that the forces observed, although small, are sufficient to allow for the insuck of the cervical mucus in which spermatozoa have been trapped after ejaculation. The cervical mucus may previously have been slightly extruded by the increased pressures observed before female orgasm. This would place importance upon the state of the cervical mucus and its spinnbarkeit, and indeed, the cervical mucus is most receptive at mid-cycle, the time most propitious for fertilization.

Certain types of infertility might in future be investigated for the nature of the uterine motility patterns and uterine pressures. When a smaller and, at the same time, longer-acting radio-pill has been developed, it will be possible to study the nature of the regular uterine contractions throughout the cycle, as well as the reactions to orgasm at different times in the cycle. The timing of female orgasm vis-à-vis the male orgasm is of some importance in the process of fertilization. A slight delay in the female orgasm may be at least as effective as simultaneous orgasm, and certainly preferable to the situation in which female orgasm precedes male orgasm.

It has been suggested by Parkes (personal communication) that while female orgasm may facilitate sperm transport, as described in this paper, it is well 
known that female orgasm is not essential for fertilization, and therefore for effective sperm transport. Our hypothesis must, therefore, be considered to explain only one, albeit the most efficient, method of fertilization. It is possible that the regular uterine contractions, which occur irrespective of orgasm, and in our tracings are abolished by orgasm, may have some significance in sperm transport as they do in some lower mammals. It may be that the achievement of orgasm in the female is necessary where the male's sperm count is low. It is of interest that there is a low conception rate in women following artificial insemination, in which the semen is usually introduced direct into the cervical canal and orgasm is most unlikely (Parkes, personal communication). Thus, the orgasm may play a rôle in fertilization through the release of hormones into the blood-stream. If the mere introduction of semen into the cervical canal is insufficient to ensure conception, it suggests that motility of the uterus is important for sperm transport into the uterus itself and into the Fallopian tube. It is known that there is a high conception rate following rape, and it is possible that, in this situation, the release of adrenaline due to fear and anger may act on the human uterus. The possible release of catecholamines in the natural coital situation is being investigated by one of the authors (G.A.F.).

\section{ACKNOWLEDGMENTS}

It is our pleasure to acknowledge the help of the following: Professor Sir Alan Parkes, for suggesting this line of research and for his help with the discussion, and his kind encouragement, Professor V. R. Pickles, for much initial discussion in methods of measuring intra-uterine pressures, and for his constant encouragement and Mr A. E. Fyfe, Gonsultant Gynaecologist, for his help and operative skill in inserting the radio-pill. Finally, we thank Dr Beatrice Fox, without whose help this investigation would not have been possible.

\section{REFERENCES}

Ammersbach, R. (1930) Sterilität und frigidität. Münch. med. Wschr. 77, 225.

Bangham, D. R., Cotes, P. M. \& Parsons, J. A. (1966) Measurement of intra-uterine pressure changes in the pregnant rhesus monkey by telemetric recording from pressure sensitive capsules inserted in the uterus. Mem. Soc. Endocr. M. 14.

Carleton, H. M. \& Florey, H. (1931) Birth control studies. I. On the ingress of semen into the uterus during coitus. 7. Obstet. Gynaec. Br. Emp. 38, 550.

Gsapo, A. I. \& Pinto-Dantas, C. R. (1966) The cyclic activity of the non-pregnant human uterus. A new method for recording intra-uterine pressure. Fert. Steril. 17, 34.

Eliasson, R. \& Posse, N. (1965) Rubin's test before and after intravaginal application of prostaglandin. Int. 7. Fert. 10, 373.

Evans, E. I. (1933) The transport of spermatozoa in the dog. Am. F. Physiol. 105, 287.

Fox, G. A. \& KNAGGs, G. S. (1969) Milk-ejection activity (oxytocin) in peripheral blood in man during lactation and in association with coitus. F. Endocr. 45, 145.

GenelL, S. (1939) Experimental investigations of the muscular functions of the vagina and the uterus in the rat. Acta obstet. gynec. scand. 19, 133.

Grafenberg, E. (1950) The role of urethra in female orgasm. Int. F. Sex. 3, 145.

Hartman, G. G. \& Ball, J. (1930) On the almost instantaneous transport of spermatozoa through the cervix and uterus of the rat. Proc, Soc. exp. Biol. Med. 28, 312.

Hendrigks, G. H. (1964) A new technique for the study of motility in the non-pregnant human uterus. 7. Obstet. Gynaec. Br. Commw. 71, 712 .

Hindson, J. G., Schofield, B. M. \& Turner, G. B. (1968) Parturient pressures in the ovine uterus. J. Physiol., Lond. 195, 19. 
Hindson, J. C., Schorield, B. M., Turner, C. B. \& Wolff, H. S. (1965) Parturition in the sheep. $\mathcal{F}$. Physiol., Lond. 181, 560.

KRehbiel, R. H. \& Carstens, H. P. (1939) Roentgen studies of the mechanism involved in sperm transportation in the female rabbit. Am. 7. Physiol. 125, 571 .

Masters, W. H. \& Johnson, V.E.(1966) Human sexual response, pp. 122-124. Churchill, London.

MiLlar, R. (1952) Forces observed during coitus in thoroughbreds. Aust. vet. 7. 28, 127.

Moawad, A. H. \& Bengtsson, L. P. (1967) In vivo studies of the motility patterns of the non-pregnant human uterus. Am. 7. Obstet. Gynec. 98, 1057.

Noyes, R. W., Adams, C. E. \& Walton, A. (1958) Transport of spermatozoa into the uterus of the rabbit. Fert. Steril. 9, 288.

Pickles, V. R. (1967) Uterine suction during orgasm. Br. med. 7. i, 427.

Stmmons, K. R., DracY, A. E. \& EssleR, W. O. (1965) Recording uterine activity by radio telemetry techniques. F. Dairy Sci. 48, 1126.

Trapl, J. (1943) Neue Anschauungen über den Ei- und Samentransport in den inneren Geschlechtsteilen der Frau. Zentbl. Gynäk. 67, 547.

VanDemark, N. L. \& Moeller, A. N. (1951) Speed of spermatozoan transport in the reproductive tract of the estrous cow. Am. F. Physiol. 165, 674.

Walton, A. (1930) On the function of the rabbit cervix during coitus. 7. Obstet. Gynaec. Br. Emp. 37, 92.

WolfF, H. S. (1961) The radio pill. New Scient. 12, 419. 